\title{
Dietary restraint moderates the effects of food exposure on women's body and weight satisfaction
}

Citation for published version (APA):

Geschwind, N., Roefs, A. J., Lattimore, P., Fett, A. J., \& Jansen, A. T. M. (2008). Dietary restraint moderates the effects of food exposure on women's body and weight satisfaction. Appetite, 51(3), 735738. https://doi.org/10.1016/j.appet.2008.05.057

Document status and date:

Published: 01/01/2008

DOI:

10.1016/j.appet.2008.05.057

Document Version:

Publisher's PDF, also known as Version of record

Document license:

Taverne

Please check the document version of this publication:

- A submitted manuscript is the version of the article upon submission and before peer-review. There can be important differences between the submitted version and the official published version of record.

People interested in the research are advised to contact the author for the final version of the publication, or visit the DOI to the publisher's website.

- The final author version and the galley proof are versions of the publication after peer review.

- The final published version features the final layout of the paper including the volume, issue and page numbers.

Link to publication

\footnotetext{
General rights rights.

- You may freely distribute the URL identifying the publication in the public portal. please follow below link for the End User Agreement:

www.umlib.nl/taverne-license

Take down policy

If you believe that this document breaches copyright please contact us at:

repository@maastrichtuniversity.nl

providing details and we will investigate your claim.
}

Copyright and moral rights for the publications made accessible in the public portal are retained by the authors and/or other copyright owners and it is a condition of accessing publications that users recognise and abide by the legal requirements associated with these

- Users may download and print one copy of any publication from the public portal for the purpose of private study or research.

- You may not further distribute the material or use it for any profit-making activity or commercial gain

If the publication is distributed under the terms of Article $25 \mathrm{fa}$ of the Dutch Copyright Act, indicated by the "Taverne" license above, 
Short communication

\title{
Dietary restraint moderates the effects of food exposure on women's body and weight satisfaction
}

\author{
Nicole Geschwind ${ }^{\mathrm{a}, *}$, Anne Roefs ${ }^{\mathrm{b}}$, Paul Lattimore ${ }^{\mathrm{c}}$, Anne-Kathrin Fett ${ }^{\mathrm{b}}$, Anita Jansen ${ }^{\mathrm{b}}$ \\ a Department of Psychiatry and Neuropsychology, South Limburg Mental Health and Teaching Network, EURON, Maastricht University, \\ P.O. Box 616, 6200 MD Maastricht, The Netherlands \\ ${ }^{\mathrm{b}}$ Department of Clinical Psychological Science, Maastricht University, P.O. Box 616, 6200 MD Maastricht, The Netherlands \\ ' School of Psychology, Liverpool John Moores University, Liverpool, UK
}

\section{A R T I C L E I N F O}

Article history:

Received 11 March 2008

Received in revised form 16 May 2008

Accepted 20 May 2008

\section{Keywords:}

Body satisfaction

Weight satisfaction

Restraint

Exposure

Food cues

High-caloric

Body image

\begin{abstract}
A B S T R A C T
The influence of dietary restraint and food exposure on body satisfaction was tested. Body and weight satisfaction were measured before and after exposure to either high- or low-caloric food, without actual eating. Independent of caloric condition, higher dietary restraint was associated with a decrease in body satisfaction after food exposure. With regard to weight satisfaction, however, the association between higher dietary restraint and decreased weight satisfaction was specific for the high-caloric condition. Thus, the actual eating of food is not necessary for decreased body and weight satisfaction to occur, suggesting an exposure-induced activation of dysfunctional cognitions in restrained eaters.
\end{abstract}

(c) 2008 Elsevier Ltd. All rights reserved.

\section{Introduction}

Body dissatisfaction is an important risk and maintenance factor for eating disorders (Graber, Brooks-Gunn, Paikoff, \& Warren, 1994; Killen et al., 1996; Stice, 2002). In contrast to earlier views of body satisfaction as a stable and trait-like feature, it is now known that body satisfaction fluctuates considerably, depending on the situation and the environment in which it is measured (Cash, Fleming, Alindogan, Steadman, \& Whitehead, 2002; Tiggemann, 2001). This fluctuation has been found to be more pronounced in people prone to body dissatisfaction (Tiggemann, 2001). Exposure to foods, in particular high-caloric foods, is expected to elicit schemas related to overeating, possibly resulting in heightened body dissatisfaction (Thompson, Coovert, Pasman, \& Robb, 1993). Therefore, the purpose of this paper is to shed light on how body satisfaction fluctuates in response to food exposure, and how this is affected by participants' restraint status and the caloric content of foods.

Concerns about weight and shape are closely related to attempts to restrict one's food intake (Herman \& Polivy, 1980).

\footnotetext{
* Corresponding author.

E-mail address: N.Geschwind@sp.unimaas.nl (N. Geschwind).
}

Exposure to food therefore is likely to activate concerns about caloric content, overeating, and related issues like body dissatisfaction in those worried about their weight and shape (Corte $\&$ Stein, 2005). Indeed, exposure to food has been found to increase body dissatisfaction and negative affect in studies with bulimic patients (Bulik, Lawson, \& Carter, 1996; Carter, Bulik, Lawson, Sullivan, \& Wilson, 1996; Legenbauer, Vögele, \& Rüddel, 2004; Mauler, Hamm, Weike, \& Tuschen-Caffier, 2006; McKenzie, Williamson, \& Cubic, 1993; Neudeck, Florin, \& Tuschen-Caffier, 2001). However, because these studies typically used patients' binge foods as food cues, a decrease in body satisfaction might largely reflect learned negative associations between binge food and bingeing/purging.

To investigate whether exposure to food affects body satisfaction independent of negative associations with bingeing and purging, it is essential to look at the effects of food exposure in people who are vulnerable to problematic eating behaviours but in all likelihood unaffected by bulimia. Restrained eaters represent such a group because they are constantly struggling with their natural appetite and their goal to lose weight (Herman \& Polivy, 1980), but rarely engage in bingeing and purging (Lowe et al., 1996). They can be considered as being on a continuum between unrestrained eaters and bulimic patients (Lowe et al., 1996). 
Studies with restrained eaters have focussed on measuring the effects of food consumption, but not food exposure, on body satisfaction. Vocks, Legenbauer, and Heil (2007) found that body satisfaction decreased after milkshake consumption. This effect was stronger in those scoring higher on restraint than in those scoring lower on restraint. In contrast, Wardle and Foley (1989) report a more pronounced decrease of body satisfaction in unrestrained eaters after food consumption, compared to restrained eaters. Overall, however, the restrained participants displayed lower levels of body satisfaction than the unrestrained participants. In a study of Pietrowsky, Straub, and Hachl (2003), restrained eaters indicated lower body satisfaction when hungry than when sated. Finally, Lattimore (2005) found that changes in body satisfaction after the consumption of a main meal were not at all moderated by dietary restraint but by body mass index. Overall, the results of these studies are inconsistent, possibly due to methodological differences (see Vocks et al., 2007). Additionally, food consumption studies pose interpretive problems because the physical effects of digestion or other bodily signals (like a bloated or rumbling stomach) cannot be distinguished from cognitive effects (e.g., the potential threat of food to dietary restraint).

To eliminate the interpretive problems with both food consumption studies and studies with bulimic patients, the present study examines the influence of high- and low-caloric food exposure on body and weight satisfaction in a nonclinical population. This allows investigating whether exposure to food affects body and weight satisfaction (a) independent of digestive effects and (b) independent of learned associations with bingeing and purging. Apart from general body satisfaction, a measure of weight satisfaction was included as well, because it taps a potentially more food-sensitive aspect of body satisfaction.

In sum, the aim of the current study is to examine whether mere exposure to high-caloric foods in comparison to low-caloric foods decreases body and weight satisfaction, and whether this relationship is moderated by dietary restraint. Because high-caloric foods should evoke cognitive schemas related to overeating more than low-caloric foods, and because high-restrained eaters are known to be concerned about their weight, it is hypothesized that specifically high-caloric food exposure leads to a decrease in body and weight satisfaction with increasing levels of restraint.

\section{Method}

\section{Measures}

Two 100-mm Visual Analogue Scale (VAS) items ("Right now, I feel not at all satisfied with my body/very satisfied with my body" and "Right now, I feel not at all satisfied with my weight/very satisfied with my weight") were used to assess body and weight satisfaction. VAS-measures have been found to be reliable and valid tools for measuring human cognition and emotion (e.g., De Boer et al., 2004; Flint, Raben, Blundell, \& Astrup, 2000). To avoid memory-effects and to maintain the cover story (see procedure), the VAS items were hidden among other, irrelevant VAS-items (e.g., "Right now, I am not at all concentrating/concentrating very much"). The VAS-items were presented in a small booklet (one item per page). The order of the VAS-items was randomized separately for the pre- and the post-measure but was the same for all participants.

\section{Procedure}

Participants were tested individually between 11 a.m. and 1 p.m. or between 3 p.m. and 5 p.m. They were asked to eat a sandwich with a normal filling approximately $2.5 \mathrm{~h}$ before their appointment and to refrain from eating and drinking anything but water from then on.
Upon arrival at the laboratory, participants were welcomed and their compliance concerning the instructions on food intake prior to the appointment was checked. All participants had complied with the instructions and were asked to sign the informed consent form. The experimenter informed the participants that they were taking part in a study on the effects of mindfulness and concentration on general well-being. This cover story was used to prevent recognition of the true purpose of the study. Then participants completed the pre-exposure set of VAS-items.

After completion of the VAS-premeasures, the cover story was elaborated in more detail. Participants were told that bowls with food would serve as stimuli for the mindfulness session. To make the food exposure more intense and realistic, participants were informed that they would be allowed to eat as much of the food as they wanted after the experiment because the food would have to be thrown away anyway (though only two participants actually ate something).

Depending on the experimental condition, bowls with either high-caloric foods (crisps, chocolate, and cake) or low-caloric foods (cucumber, carrot and pepper) were presented one by one. Except for the bowl of crisps (which only contained $50 \mathrm{~g}$ due to the crisps' high volume), each bowl contained $100 \mathrm{~g}$ of food. The experimenter modelled the exposure procedure during which the participants were asked to look at the food, pay attention to its texture, smell the food, and lick the food. They were asked to pay attention to the thoughts and feelings the foods elicited. The exposure lasted approximately $2 \mathrm{~min}$ per food item.

After the exposure to all foods was completed, participants filled in the postmeasure set of VAS-items. Participants were then given the opportunity to eat as much as they wanted, and an appointment for the second session (approximately 1 week later) was made.

During this second session, the participants filled in the Restraint Scale (RS; Herman \& Polivy, 1980), and the Dutch Eating Behaviour Questionnaire (DEB-Q; Van Strien, Frijters, Bergers, \& Defares, 1986). After that, participants' weight and height were measured using standard equipment. Finally, participants were thanked for their participation and paid. A complete debriefing was sent to them at the end of the study.

\section{Participants}

Sixty-five female first-year students were recruited for participation through announcements during lectures. Participants received either course credits or 10 Euros at the end of the experiment. This study was approved by the local ethics committee. Participants were randomly assigned to either the high- or the low-caloric condition. Five participants were excluded because their body mass index (BMI; $\mathrm{kg} / \mathrm{m}^{2}$ ) was lower than 18 or higher than 30, leaving 30 participants in the high-caloric condition (age: $M=18.7$, S.D. $=1.9$; RS: $M=11.5$, S.D. $=4.6$; DEB$\mathrm{Q}$ emotional eating: $M=2.6$, S.D. $=0.7$; DEB-Q external eating: $M=3.0$, S.D. $=0.4$; DEB-Q restrained eating: $M=2.7$, S.D. $=0.9$; BMI: $M=22.0$, S.D. $=2.5$ ), and 30 participants in the low-caloric condition (age: $M=18.8$, S.D. $=1.0$; RS: $M=11.9$, S.D. $=4.4$; DEB-Q emotional eating: $M=2.6$, S.D. $=0.6$; DEB-Q external eating: $M=3.0$, S.D. $=0.4$; DEB-Q restrained eating: $M=3.0$, S.D. $=0.8$; BMI: $M=22.2$, S.D. $=2.4$ ). Independent $t$-tests indicated that there were no significant differences between conditions on RS, BMI, and DEBQ measures, all $p>0.15$.

\section{Data analysis}

To examine our hypothesis that specifically high-caloric food exposure leads to a decrease in body satisfaction with increasing 
levels of restraint, linear regression analyses were performed. The dependent variables were change in body satisfaction and change in weight satisfaction, computed as post- minus pre-exposure scores of the body and weight satisfaction items, respectively. After centering (value minus mean value) the variable restraint and coding the variable caloric condition as 1 and -1 , we confirmed that our data met the requirements for regression modelling (no collinearity problems, outliers, or influential cases, no deviations from normality, no heteroskedasticity). The independent variables caloric condition and restraint and their interaction term were simultaneously entered into a separate regression model for each dependent variable. If an interaction term was not significant, the analysis was repeated without the interaction term, and the reported main effects then refer to the analysis without the interaction term.

\section{Results}

\section{Change in body satisfaction}

Contrary to our expectation that specifically high-caloric food exposure would lead to a decrease in body satisfaction with increasing levels of restraint, the interaction between dietary restraint and caloric condition was not significant, $p>0.9$. The effect of caloric condition was not significant either, $p>0.3$. The only significant predictor of lowered body satisfaction was dietary restraint, $\beta=-0.26, t=2.04, p<0.05, R^{2}=0.12$, indicating that the higher participants' restraint score, the less satisfied they became with their bodies after food exposure, independent of the caloric condition.

\section{Change in weight satisfaction}

In line with our hypothesis, the interaction between dietary restraint and caloric condition was significant, $\beta=-0.29, t=2.27$, $p<0.05, R^{2}=0.09$. For the main effects of caloric condition and restraint, $p$ were $>0.4$. The interaction term was further analysed by performing separate regression analyses per caloric condition. In the high caloric group, higher dietary restraint scores tended to be associated with decreased satisfaction with weight after exposure to food, $\beta=-0.31, t=-1.76, p=0.09, R^{2}=0.10$. In the low caloric group, there was no significant association between dietary restraint and change in weight satisfaction, $p>0.15$.

While premeasures of body and weight satisfaction were highly correlated across the whole sample, $r=0.8, p<0.001$, changes in body and weight satisfaction were hardly correlated, $r=0.1$, $p>0.3$.

\section{Discussion}

Because high-caloric foods should evoke cognitive schemas related to overeating more than low-caloric foods, and because high-restrained eaters are known to be concerned about their weight, it was hypothesized that specifically high-caloric food exposure would lead to decreases in body and weight satisfaction with increasing levels of restraint.

Concerning change in satisfaction with weight, the results supported our hypothesis. In the high-caloric condition, higher restraint scores tended to be associated with decreases in participants' satisfaction with their weight, whereas there was no such relationship in the low-caloric condition. This finding can be seen as a synthesis of results of Thompson et al. (1993) who manipulated caloric content but did not measure restraint, and results of Vocks et al. (2007) who measured restraint but did not manipulate caloric content. Thompson et al. (1993) found that participants who believed they had consumed a high-caloric milkshake overestimated their body size more at posttest than participants who believed they had consumed a low-caloric milkshake. Vocks et al. (2007) found that the negative effect of milkshake consumption on body image increased with dietary restraint. It is intriguing, and that is what the present study adds, that actual eating is not necessary for decreased satisfaction to occur. Concerning change in satisfaction with body, our hypothesis was only partially supported, as dietary restraint was associated with decreases in body satisfaction after food exposure independent of caloric condition. The higher participants' restraint score, the more dissatisfied they became with their bodies after both high- and low-caloric food exposure.

The finding that high- and low-caloric food exposure had a different effect on participants' body versus weight satisfaction indicates that weight satisfaction may be more closely and more explicitly coupled to caloric information than body satisfaction. The related concern that our results might be confounded by social desirability was minimized by using a cover story and hiding the dependent variables among irrelevant items. This represents a strong feature of the present study and adds weight to the novel finding that decreased satisfaction after food exposure is independent of both actual eating and learned associations with bingeing and purging. However, our instructions not to eat anything prior to testing might have partially revealed the true purpose of the study. Therefore, future research might consider using a more indirect measure (e.g., response latency paradigm adopted from cognitive psychology) as an outcome measure (instead of self-report) to make social desirability even more unlikely.

\section{Acknowledgements}

This study was presented at the British Feeding \& Drinking Group Annual Meeting hosted by Northumbria University, UK. The project was partially funded by an award to Lattimore, Roefs, and Jansen from the British Academy for the Humanities and the Social Sciences, Grant No. LRG-4152.

\section{References}

Bulik, C. M., Lawson, R. H., \& Carter, F. A. (1996). Salivary reactivity in restrained and unrestrained eaters and women with bulimia nervosa. Appetite, 27, 15-24.

Carter, F. A., Bulik, C. M., Lawson, R. H., Sullivan, P. F., \& Wilson, J. S. (1996). Effect of mood and food cues on body image in women with bulimia and controls. International Journal of Eating Disorders, 20, 65-76.

Cash, T. F., Fleming, E. C., Alindogan, J., Steadman, L., \& Whitehead, A. (2002). Beyond body image as a trait: The development and validation of the Body Image States Scale. Eating Disorders, 10, 103-113.

Corte, C., \& Stein, K. F. (2005). Body-weight self-schema: Determinant of mood and behavior in women with an eating disorder. Journal of Applied Social Psychology, 35, 1698-1718

De Boer, A. G. E. M. , Van Lanschot, J. J. B., Stalmeier, P. F. M., Van Sandick, J. W., Hulscher, J. B. F., De Haes, J. C. J., et al. (2004). Is a single-item visual analogue scale as valid, reliable and responsive as multi-item scales in measuring quality of life? Quality of Life Research, 13, 311-320.

Flint, A., Raben, A., Blundell, J. E., \& Astrup, A. (2000). Reproducibility, power and validity of visual analogue scales in assessment of appetite sensations in single test meal studies. International Journal of Obesity, 24, 38-48.

Graber, J. A., Brooks-Gunn, J., Paikoff, R. L., \& Warren, M. P. (1994). Prediction of eating problems: An 8-year study of adolescent girls. Developmental Psychology, 30, 823834.

Herman, C. P., \& Polivy, J. (1980). Restrained eating. In A. J. Stunkard (Ed.), Obesity (pp. 208-225). Philadelphia: Sauders.

Killen, J. D., Taylor, C. B., Hayward, C., Haydel, K. P., Wilson, D. M., Hammer, L., et al. (1996). Weight concerns influence the development of eating disorders: A 4-year prospective study. Journal of Consulting and Clinical Psychology, 64, 936-940.

Lattimore, P. (2005). Body dissatisfaction varies according to deprivation state and is modified by weight rather than restraint status. Appetite, 45, 356-359.

Legenbauer, T., Vögele, C., \& Rüddel, H. (2004). Anticipatory effects of food exposure in women diagnosed with bulimia nervosa. Appetite, 42, 33-40. 
Lowe, M. R., Gleaves, D. H., McKinney, S., DiSimone-Weiss, R. T., Furgueson, C., Gayda, C. A., et al. (1996). Restraint, dieting, and the continuum model of bulimia nervosa. Journal of Abnormal Psychology, 105, 508-517.

Mauler, B. I., Hamm, A. O., Weike, A. I., \& Tuschen-Caffier, B. (2006). Affect regulation and food intake in bulimia nervosa: Emotional responding to food cues after deprivation and subsequent eating. Journal of Abnormal Psychology, 115, 567-579.

McKenzie, S. J., Williamson, D. A., \& Cubic, B. A. (1993). Stable and reactive body image disturbances in bulimia nervosa. Behavior Therapy, 24, 195-207.

Neudeck, P., Florin, I., \& Tuschen-Caffier, B. (2001). Food exposure in patients with bulimia nervosa. Psychotherapy and Psychosomatics, 70, 193-200.

Pietrowsky, R., Straub, K., \& Hachl, P. (2003). Body dissatisfaction in female restrained eaters depends on food deprivation. Appetite, 40, 285-290.

Stice, E. (2002). Risk and maintenance factors for eating pathology: A meta-analytic review. Psychological Bulletin, 128, 825-848.
Thompson, J. K., Coovert, D. L., Pasman, L. N., \& Robb, J. (1993). Body image and food consumption: Three laboratory studies of perceived calorie content. International Journal of Eating Disorders, 14, 445-457.

Tiggemann, M. (2001). Person $\times$ situation interactions in body dissatisfaction. International Journal of Eating Disorders, 29, 65-70.

Van Strien, T. Frijters, J. E. R., Bergers, G. P. A. \& Defares, P. B. (1986). The Dutch Eating Behavior Questionnaire (DEBQ) for assessment of restrained, emotional, and external eating behavior. International Journal of Eating Disorders, 5, 295315.

Vocks, S., Legenbauer, T., \& Heil, A. (2007). Food intake affects state body image: Impact of restrained eating patterns and concerns about eating, weight and shape. Appetite, 49, 467-475.

Wardle, J., \& Foley, E. (1989). Body image: Stability and sensitivity of body satisfaction and body size estimation. International Journal of Eating Disorders, 8, 55-62. 